$13^{\text {th }}$ International Conference on

\title{
Statistical-Based Models for Behavior of Flexible Pavements
}

\author{
A. El-Desouky ${ }^{*}$
}

\begin{abstract}
The main objective of this paper was to provide some useful statistical-based models for flexible pavement behavior. The results of a theoretical analysis, using the finite element (FE) program SAP was utilized in this statistical analysis study. The maximum surface deflection, the maximum horizontal tensile strain $\left(\varepsilon_{t}\right)$ at the bottom of AC layer and the maximum compressive strain $\left(\varepsilon_{c}\right)$ at the top of subgrade are the most commonly used criteria for flexible pavement design. They were used in this study as the basis for measuring the flexible pavement response. The Statistical Package for Social Sciences (SPSS) version 11.0 was used to relate these parameters to the basic flexible pavement layer properties. Clearly, the properties of the top layer, asphalt concrete (AC) layer, are the key to control the behavior of flexible pavements. Based on that, the models developed in this paper concerned with the thickness and modulus of AC layer. Three different AC thicknesses and eight different AC moduli were used to investigate the response of flexible pavement. Based on the theoretical and statistical work presented in this study, simple statistical-based models for the response of flexible pavements were developed. These models could be easily used by pavement engineers to predict the flexible pavement indicators; maximum surface deflection, maximum horizontal tensile strain at the bottom of asphalt concrete layer and maximum vertical compressive strain at the top of subgrade layer. The presented models emphasized that the thickness of asphalt concrete layer was the most important independent variable for the response of flexible pavement followed by the modulus of AC layer.
\end{abstract}

Keywords: Flexible pavements, finite elements, and statistical analysis.

\section{Introduction}

More and more flexible pavement designs are being based on a mechanistic approach. In a mechanistic design procedure, structural analysis tools or computer programs are required to predict the stress-strain and displacement response of pavements. A number of computer programs based on the FE or the multilayered elasticity (MLE) method have been developed and used for structural analysis of flexible pavement. The results may vary among analysts because of the assumptions made in each procedure and the different input assigned by individual analysts. Thus, selection of an appropriate computer program for structural analysis of flexible pavements is a challenge for the pavement engineers.

\footnotetext{
* Egyptian Armed Forces, Egypt.
} 
The flexible pavement structure was assumed to have three layers (AC, untreated base, and subgrade). The interface between any two consecutive layers was assumed to be perfectly bonded as recommended by the asphalt institute [1]. The main objective of this study was to relate the parameters measuring the flexible pavement behavior to the AC layer properties. Based on these parameters, pavement life in terms of allowable number of load repetitions based on fatigue cracking $\left(\mathrm{N}_{\mathrm{f}}\right)$ and allowable number of load repetitions to control permanent deformation $\left(\mathrm{N}_{\mathrm{d}}\right)$ could be calculated. The $\mathrm{FE}$ analysis of flexible pavement response was carried out using the FE computer program SAP. SAP is a FE structural analysis program deals with linear elastic materials [2]. All necessary geometric and loading options associated with the elements have been incorporated. The sensitivity analysis was focused on the effect of AC layer thickness $\left(h_{1}\right)$ and AC layer modulus $\left(E_{1}\right)$ on the maximum surface deflection, the maximum tensile strain at the bottom of the AC layer, and the maximum compressive strain at the top of subgrade. They are the most commonly used criteria for flexible pavement design $[3,4,5]$, and were used in this paper as the basis for measuring the flexible pavement behavior. Stresses and surface deflections were obtained directly from the FE solution phase. Strains were calculated from the relationships of isotropic materials that assumed in this study. A number of researchers studied the effect of $E_{1}$ on the flexible pavements behavior. For example, Yue et al. [6] studied the flexible pavement response under different tirepavement contact pressures. They found that, $\varepsilon_{\mathrm{t}}$ decreased as $\mathrm{E}_{1}$ increased. However, in cases of high-strength bases there was a critical $\mathrm{E}_{1}$ value below which $\varepsilon_{\mathrm{t}}$ also decreased.

\section{Finite Element Models}

The flexible pavement structure was assumed to have three layers (asphalt concrete, untreated base, and subgrade). The interface between any two consecutive layers was assumed to be perfectly bonded as recommended by the asphalt institute [1]. The properties required for each layer were the thickness (h), Poisson's ratio ( $v$ ), and modulus of elasticity (E). The layer properties data are; $E_{1}$ ranged from 500 to $3000 \mathrm{MPa}, \mathrm{E}_{2}=250 \mathrm{MPa}$, and $\mathrm{E}_{3}=50 \mathrm{MPa}$. The Poisson's ratios were $v_{1}=0.35, v_{2}=0.30$, and $v_{3}=0.40$. The thicknesses of the layers were $h_{1}$ varied from 5 to $15 \mathrm{~cm}, \mathrm{~h}_{2}=25 \mathrm{~cm}$, and $\mathrm{h}_{3}=90 \mathrm{~cm}$ such that the depth of the finite element model was taken $\geq$ four times the diameter of the wheel-pavement contact area $(\mathrm{d}=30 \mathrm{~cm}$ as mentioned later), so the stresses at this depth were very small. The analysis model was established with a fixed boundary at the bottom and roller supports on sides. A single wheel load of $40 \mathrm{kN}$ was applied over a circular contact area of $30 \mathrm{~cm}$ diameter [7, 8, 9].

\section{Results of Finite Element Analysis}

\subsection{Maximum Surface Deflection}

The maximum surface deflection for AC layer thickness of 5, 10, and $15 \mathrm{~cm}$ are presented in Table 1. It was found that the maximum surface deflection decreased by increasing $\mathrm{E}_{1}$. The percentage decreases due to increasing $\mathrm{E}_{1}$ from 500 to $3000 \mathrm{MPa}$ were $11.07 \%, 22.37 \%$, and $30.82 \%$ for $h_{1}=5,10$, and $15 \mathrm{~cm}$, respectively. The thickness $h_{1}$ has a significant effect on the maximum surface deflection, with increasing $\mathrm{h}_{1}$ the maximum surface deflection decreased considerably. The maximum surface deflection decreased by $13.12 \%$ and $22.97 \%$ due to increasing $h_{1}$ from $5 \mathrm{~cm}$ to $10 \mathrm{~cm}$ and $15 \mathrm{~cm}$, respectively for $\mathrm{E}_{1}=500 \mathrm{MPa}$, and by $24.16 \%$ and $40.08 \%$ for $\mathrm{E}_{1}=3000 \mathrm{MPa}$. The percentage of reduction in the maximum surface deflection increased for higher $\mathrm{E}_{1}$ values. 
Table 1. Maximum Surface Deflection for Different $E_{1}$ and $h_{1}$ Values

\begin{tabular}{|c|c|c|c|c|c|c|c|c|}
\hline \multirow{3}{*}{$\mathrm{E}_{1}(\mathrm{MPa})$} & \multicolumn{8}{|c|}{ AC layer thickness $\mathrm{h}_{1}(\mathrm{~cm})$} \\
\hline & \multicolumn{2}{|c|}{5} & \multicolumn{3}{|c|}{10} & \multicolumn{3}{|c|}{15} \\
\hline & (1) & (2) & (1) & $(2)$ & (3) & (1) & $(2)$ & (3) \\
\hline 500 & 1.251 & --- & 1.087 & --- & 13.12 & 0.964 & --- & 22.97 \\
\hline 750 & 1.220 & 2.55 & 1.031 & 5.19 & 15.48 & 0.887 & 8.03 & 27.30 \\
\hline 1000 & 1.198 & 4.28 & 0.993 & 8.69 & 17.13 & 0.837 & 13.17 & 30.13 \\
\hline 1250 & 1.181 & 5.59 & 0.964 & 11.37 & 18.44 & 0.800 & 16.96 & 32.25 \\
\hline 1500 & 1.168 & 6.67 & 0.940 & 13.59 & 19.56 & 0.771 & 19.97 & 33.04 \\
\hline 2000 & 1.146 & 8.42 & 0.901 & 17.14 & 21.40 & 0.727 & 24.58 & 36.94 \\
\hline 2500 & 1.128 & 9.85 & 0.870 & 19.99 & 22.89 & 0.693 & 28.06 & 38.53 \\
\hline 3000 & 1.113 & 11.07 & 0.844 & 22.37 & 24.16 & 0.667 & 30.82 & 40.08 \\
\hline
\end{tabular}

(1) maximum surface deflection (mm), downward.

(2) \%-age decrease in maximum surface deflection by increasing $\mathrm{E}_{1}$ from $500 \mathrm{MPa}$.

(3) \%-age decrease in maximum surface deflection by increasing $\mathrm{h}_{1}$ from $5 \mathrm{~cm}$.

\subsection{Maximum Horizontal Tensile Strain at the Bottom of the AC Layer}

Table 2 shows the effect of $h_{1}$ and $E_{1}$ on maximum tensile strain at the bottom of AC layer. Generally, $\varepsilon_{\mathrm{t}}$ decreased when $\mathrm{h}_{1}$ increased. In addition, when applying a vertical wheel load to the pavement system, there was a so-called critical modulus $E_{1}$ at which maximum $\varepsilon_{t}$ value existed. Below this critical modulus, the lower the asphalt concrete modulus, the smaller the value of $\varepsilon_{t}$. This confirms the findings of Yue et al. [6]. The critical modulus $\mathrm{E}_{1}$ was 2000 $\mathrm{MPa}$ for $\mathrm{h}_{1}=5 \mathrm{~cm}$, and decreased to $1500 \mathrm{MPa}$, and $750 \mathrm{MPa}$ for $\mathrm{h}_{1}=10 \mathrm{~cm}$ and $15 \mathrm{~cm}$, respectively.

\section{Table 2. Maximum Horizontal Tensile Strain $\left(\times 10^{-4}\right)$ at the Bottom of AC Layer}

\begin{tabular}{c|c|c|c}
\hline \multirow{2}{*}{$\mathrm{E}_{1}(\mathrm{MPa})$} & \multicolumn{3}{|c}{ AC layer thickness $\mathrm{h}_{1}(\mathrm{~cm})$} \\
\cline { 2 - 4 } & 5 & 10 & 15 \\
\hline 500 & 1.681 & 3.298 & 3.558 \\
750 & 2.033 & 3.110 & 3.714 \\
1000 & 2.196 & 3.070 & 3.612 \\
1250 & 2.279 & 3.190 & 3.451 \\
1500 & 2.321 & 3.216 & 3.283 \\
2000 & 2.346 & 3.153 & 2.973 \\
2500 & 2.335 & 3.036 & 2.709 \\
3000 & 2.308 & 2.908 & 2.486 \\
\hline
\end{tabular}

\subsection{Maximum Vertical Compressive Strain at the Top of the Subgrade Layer}

The effect of $E_{1}$ on $\varepsilon_{c}$ is presented in Table 3 for the different $h_{1}$ values. It was found that, $\varepsilon_{c}$ decreased by increasing $E_{1}$. The thickness $h_{1}$ had a pronounced effect on the maximum compressive strain at the top of the subgrade layer. The table also shows that $\varepsilon_{\mathrm{c}}$ decreased considerably by increasing $h_{1}$, this confirms the findings of Yue et al. [6]. 
Generally, Table 1 and Table 3 show the advantages of using higher asphalt concrete modulus regarding to maximum surface deflection and maximum vertical compressive strain at the top of the subgrade layer.

Table 3. Variation of Maximum Vertical Compressive Strain at the top of the Subgrade

\begin{tabular}{|c|c|c|c|c|c|c|c|c|}
\hline \multirow{3}{*}{$\mathrm{E}_{1}(\mathrm{MPa})$} & \multicolumn{8}{|c|}{ AC layer thickness $\mathrm{h}_{1}(\mathrm{~cm})$} \\
\hline & \multicolumn{2}{|c|}{5} & \multicolumn{3}{|c|}{10} & \multicolumn{3}{|c|}{15} \\
\hline & $(1)$ & $(2)$ & (1) & $(2)$ & (3) & (1) & (2) & (3) \\
\hline 500 & 66.44 & -- & 50.81 & -- & 23.53 & 39.00 & -- & 41.30 \\
\hline 750 & 64.28 & 3.26 & 47.70 & 6.12 & 25.79 & 35.39 & 9.27 & 44.95 \\
\hline 1000 & 62.74 & 5.57 & 45.40 & 10.64 & 27.64 & 32.73 & 16.07 & 47.83 \\
\hline 1250 & 61.56 & 7.34 & 43.55 & 14.28 & 29.25 & 30.62 & 21.48 & 50.26 \\
\hline 1500 & 60.58 & 8.82 & 41.98 & 17.37 & 30.70 & 28.87 & 25.99 & 52.35 \\
\hline 2000 & 58.95 & 11.28 & 39.39 & 22.48 & 33.18 & 26.04 & 33.23 & 55.82 \\
\hline 2500 & 57.63 & 13.27 & 37.25 & 26.68 & 35.36 & 23.83 & 38.90 & 58.65 \\
\hline 3000 & 56.49 & 14.98 & 35.44 & 30.25 & 37.26 & 22.02 & 43.54 & 61.02 \\
\hline
\end{tabular}

(1) maximum vertical compressive strain $\left(\times 10^{-4}\right)$ at the top of subgrade.

(2) \% age decrease in maximum vertical compressive strain by increasing $E_{1}$ from 500 MPa.

(3) \% age decrease in maximum vertical compressive strain by increasing $\mathrm{h}_{1}$ from $5 \mathrm{~cm}$.

\section{Statistical-Based Models}

This section includes the statistical analysis of FE results. Linear regression analysis was used utilizing the Statistical Package for Social Sciences (SPSS) version 11.0 [10]. The regression analysis was performed assuming that; the random errors have normal distribution with mean equal to 0.0, any two random errors are independent, and the random errors have equal variances. Many transformations and combinations of the independent variables were performed and included in the statistical study. The models were developed using the stepwise method.

The first set of developed models was to relate maximum surface deflection (SD) to the AC layer properties as follows;

$$
\begin{aligned}
& S D=1.331-3.28 \times 10^{-2} h_{1}-3.37 \times 10^{-5} E_{1}, \quad \mathrm{R}^{2}=0.74 \\
& S D=1.293-3.31 \times 10^{-2} h_{1}, \quad \mathrm{R}^{2}=0.72 \\
& S D=1.171-1.75 \times 10^{-3} h_{1}^{2}, \quad \mathrm{R}^{2}=0.74
\end{aligned}
$$

The second set of developed models was to predict the maximum horizontal tensile strain (TS) at the bottom of AC layer from the basic layer properties of AC. Many transformations and combinations of independent variables were used to develop the following models; 


$$
\begin{aligned}
& T S=0.226+0.4 h_{1}-1.7 \times 10^{-3} E_{1}+1.9 \times 10^{-4} h_{1} E_{1}-1.9 \times 10^{-2} h_{1}^{2}, \quad \mathrm{R}^{2}=0.87 \\
& +6.8 \times 10^{-8} E_{1}-2.9 \times 10^{-9} h_{1}^{2} E_{1}^{2}+4.8 \times 10^{-3} E_{1} / h_{1} \\
& T S=1.943+9.732 \times 10^{-2} h_{1}+1.017 \times 10^{-4} E_{1}-1.33 \times 10^{-5} h_{1} E_{1}, \quad \mathrm{R}^{2}=0.46 \\
& T S=2.091+8.201 \times 10^{-2} h_{1}-2.97 \times 10^{-5} E_{1}, \quad \mathrm{R}^{2}=0.46
\end{aligned}
$$

The last set of equations was to relate the layer properties of AC layer to the maximum vertical compressive strain (CS) at the top of subgrade. Equations (7-8) present the developed models;

$$
\begin{aligned}
& C S=83.050-3.433 h_{1}-3.08 \times 10^{-2}\left(E_{1} / h_{1}\right), \quad \mathrm{R}^{2}=0.92 \\
& C S=70.311-2.679 h_{1}, \quad \mathrm{R}^{2}=0.88
\end{aligned}
$$

where:

$\mathrm{SD}=$ maximum surface deflection $(\mathrm{mm})$

$\mathrm{TS}=$ maximum horizontal tensile strain at the bottom of the AC layer $\left(\times 10^{-4}\right)$

$\mathrm{CS}=$ maximum vertical compressive strain at the top of the subgrade $\left(\times 10^{-4}\right)$

$\mathrm{h}_{1}=$ thickness of AC layer $(\mathrm{cm})$

$\mathrm{E}_{1}=$ modulus of AC layer $(\mathrm{MPa})$

The assumptions of the linear regression analysis for all developed models in this study were checked by plotting the residuals versus the fitted values. All plots showed random scatter of points about zero and they did not show any specific pattern. Fig. (1-3) show examples of the residual plots for each set of developed models.

Based on their $\mathrm{R}^{2}$ values, Equations (5-6) are not recommended to be used to estimate tensile strains at the bottom of AC layers of flexible pavements. Equations (1, 4 and 7) were chosen to predict the flexible pavement indicators (SD, TS and CS). These equations have the highest $\mathrm{R}^{2}$ values of $0.74,0.87$ and 0.92 , which indicated that a large amount of the variation in the predicted variables could be explained by the independent variables included in these models. In addition, the selected equations have more independent variables compared to the ignored equations. Based on the significance of each independent variable of the developed models, it was found that $h_{1}$ was more significant than $E_{1}$. In other words, the flexible pavement indicators could be estimated as functions of $h_{1}$ only which could explain a large amount of variations in these indicators. More variation in the flexible pavement indicators could be explained by the modulus of AC layer $\mathrm{E}_{1}$. 


\section{Scatterplot}

Dependent Variable: SD

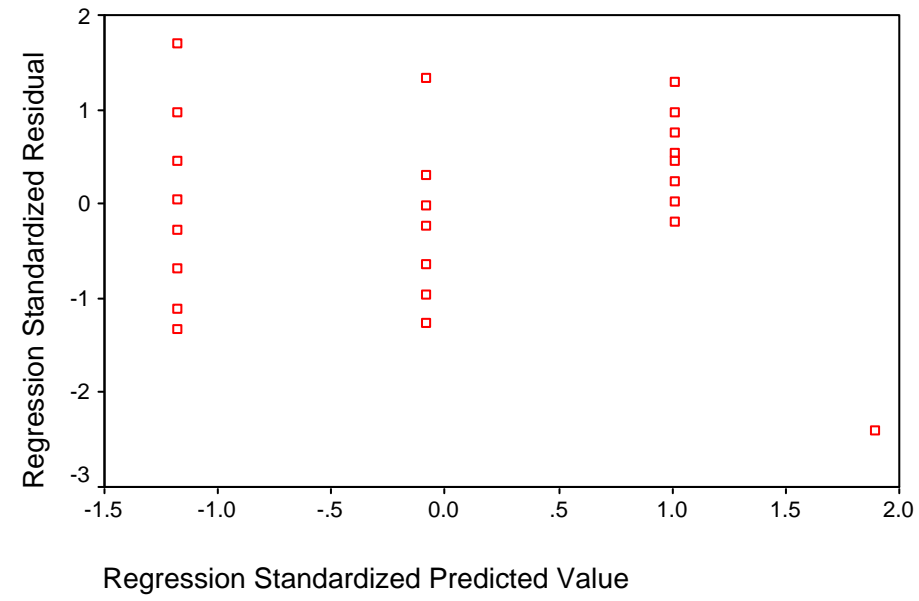

Fig. 1. Scatter plot of residuals for statistical-based model presented in Equation (2)

Scatterplot

Dependent Variable: TS

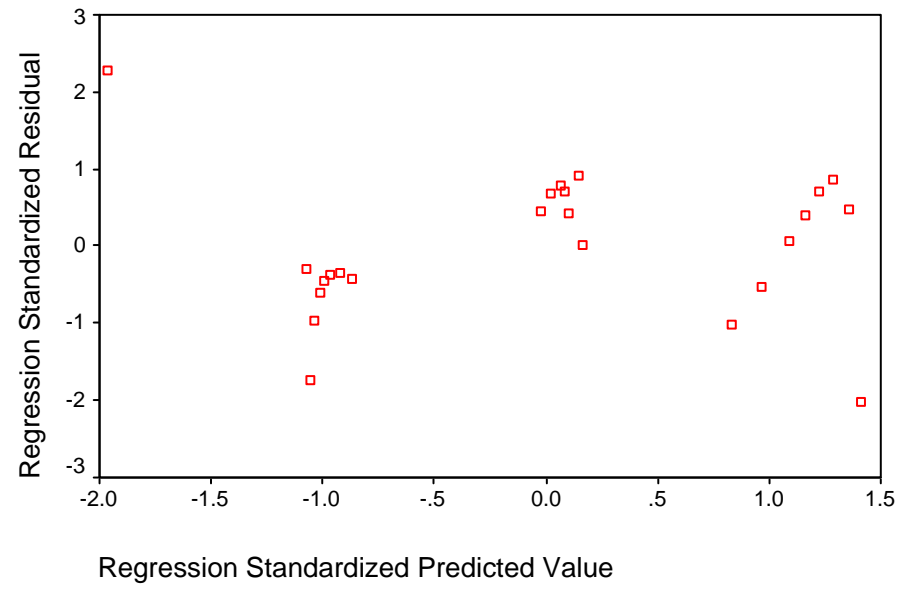

Fig. 2. Scatter plot of residuals for statistical-based model presented in Equation (5) 
Scatterplot

Dependent Variable: CS

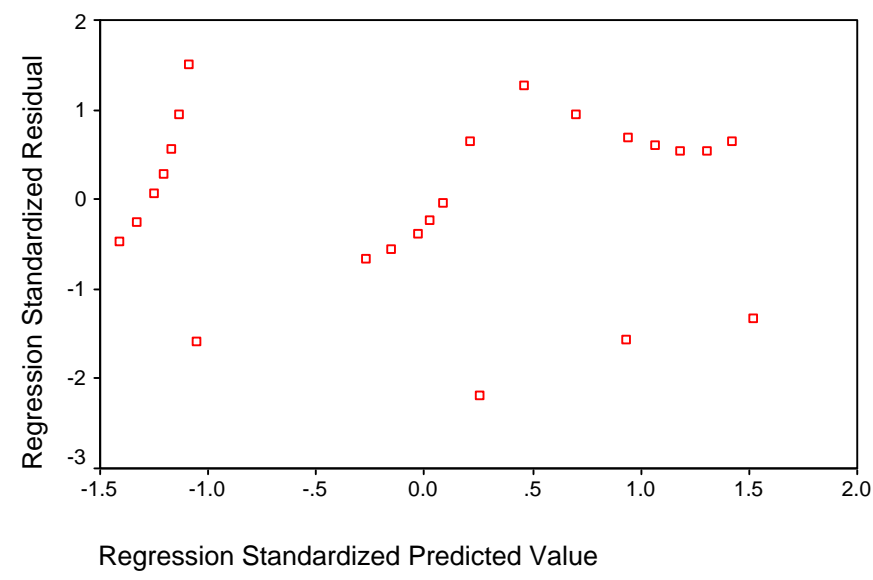

Fig. 3. Scatter plot of residuals for statistical-based model presented in Equation (7)

\section{Conclusions}

Based on the theoretical and statistical work presented in this study, the following could be concluded;

The paper presented simple statistical-based models for the response of flexible pavement. These models could be easily used by pavement engineers to predict; maximum surface deflection, maximum horizontal tensile strain at the bottom of asphalt concrete layer and maximum vertical compressive strain at top of the subgrade layer, which are the most commonly used criteria for flexible pavement design and analysis.

The presented models emphasized that the thickness of asphalt concrete layer was the most important independent variable for the response of flexible pavement followed by the modulus of AC layer.

Large amount in the variation of the flexible pavement indicators could be explained by the asphalt concrete thickness $\left(\mathrm{h}_{1}\right)$.

\section{References}

[1] The Asphalt institute. “Thickness Design - Asphalt Pavements for Highways and Streets”, Manual Series No. 1 (MS - 1), September 1981.

[2] Wilson, E. L. and Habibullah, A. "SAP90 - A Series of Computer Programs for the Finite Element Analysis of Structures - Structural Analysis User's Manual,” Computers and Structures, Inc., Berkeley, California, 1992.

[3] Huang, Y. H. "Pavement Analysis and Design. Prentice-Hall”, Englewood Cliffs, N. J., 1993.

[4] Thompson, M., et al. "Calibrated Mechanistic Structural Analysis Procedures for Pavement”, NCHRP Report 1-26, Washington, D. C., 1992. 
[5] Monismith, C. L. “Analytically Based Asphalt Pavement Design and Rehabilitation”, Theory to Practice, 1962-1992. In Transportation Research Record 1388, TRB, National Research Council, Washington, D. C., 1992, pp. 5-26.

[6] Yue, Z. Q. and Svec, O. J. "Effects of Tire-Pavement Contact Pressure Distributions on the Response of Asphalt Concrete Pavements”, Can. J. Civ. Eng. Vol. 22, 1995.

[7] Uddin W., Zhang, D. and Fernandez, F. "Finite Element Simulation of Pavement Discontinuities and Dynamic Load Response”, Department of Civil Engineering, University of Mississippi, University, Miss. 38677. Transportation Research Record 1448, pp. 100-106, 1994.

[8] Wong, J. Y. “Theory of ground vehicles”, A Wiley - Interscience Publication, John Wiley \& Sons, 1993.

[9] El-Desouky, A., Khedr, S. A. and El-Sayed, A. A. "Variation of Flexible Pavement Behavior with Asphalt Concrete Modulus under Various Wheel Loads", Third International Conference on Civil \& Architecture Engineering, MTC, Cairo, Egypt, March 1999.

[10] Statistical Package for Social Sciences (SPSS) for Windows, Version 11, User's Manual, SPSS Inc., Microsoft Corporation, 2004. 